Article

\title{
Is the Achievement of "Good Status" for German Surface Waters Disproportionately Expensive?-Comparing Two Approaches to Assess Disproportionately High Costs in the Context of the European Water Framework Directive
}

\author{
Bernd Klauer *, Johannes Schiller and Katja Sigel \\ Department of Economics, Helmholtz Centre for Environmental Research-UFZ, \\ Permoserstr. 15, D-04318 Leipzig, Germany; johannes.schiller@ufz.de (J.S.); katja.sigel@ufz.de (K.S.) \\ * Correspondence: bernd.klauer@ufz.de; Tel.: +49-341-235-1702
}

Received: 20 June 2017; Accepted: 17 July 2017; Published: 25 July 2017

\begin{abstract}
Currently only $8.2 \%$ of German surface water bodies have reached the goal of the European Water Framework Directive to bring all water into a "good status". For all water bodies that presumably will not achieve the objective by 2027 , the member states have to justify an exemption by 2021, for example, by arguing that the costs of achieving "good status" would be "disproportionately high". In this paper, two approaches for assessing cost-disproportionality of surface water bodies are empirically tested and compared on a set of real-world data from a German federal state. In the first approach, called average cost approach, costs are considered as being disproportionately high if they are significantly higher than what would be a "relatively normal effort". The core idea of the second, the benchmark approach, is to take the past public expenditures on water management as a basis for comparison. Both approaches include generated utility for determination of a water-body-specific disproportionality threshold. While the benchmarking approach needs less data, the empirical tests indicate that both approaches yield comparable results and are suitable to support authorities in the decision as to which water bodies are to be considered disproportionately expensive such that exemptions are justified.
\end{abstract}

Keywords: European Water Framework Directive; sustainable water resources management; exemption; disproportionate costs; cost-benefit analysis; affordability; surface water body

1. Introduction: The Crucial Role of Assessing "Disproportionality of Cost" within the Implementation Process of the EU Water Framework Directive

\subsection{The Dilemma of the EU Water Framework Directive}

The densely populated landscapes in Germany and Central Europe can typically be characterised as cultural landscapes which have been altered and shaped by man for centuries. Particularly in the 19th and 20th centuries, rivers have been massively modified and dammed in order to avoid flooding, to improve shipping conditions, and to enhance agricultural use of river banks. Especially in Northern Germany, huge swamps and wetlands have been drained in order to gain land for agriculture and settlements [1]. These intentional and in many respects successful alterations of the landscapes also resulted in an intensive use of nature, with degradations and threats to a sustainable provision of ecosystem services [2].

This rather fundamental conflict between the utilisation of landscapes and natural resources for economic or-more generally speaking—human purposes, on the one hand, and the protection 
of nature, on the other hand, is mirrored by a topical discussion in the field of water resources management: the implementation of the European Water Framework Directive (WFD). The central environmental objective of the directive is stated in Art. 4.1: a "good water status" should be reached in all surface waters, coastal waters and groundwater by 2015. The sub-goal of a "good ecological water status" for surface waters is defined as a status where "[ $\mathrm{t}]$ he values of the biological quality elements [... ] show low levels of distortion resulting from human activity, but deviate only slightly from those normally associated with the surface water body type under undisturbed conditions" (WFD, Annex V, Table 1.2). In other words, this central environmental objective of the directive aims at reversing the originally intended "anthropogenic alterations" of rivers and proposes developments "back to nature". The considerable efforts by the water authorities in implementing WFD, however, have not been crowned with corresponding success: as yet, only $8.2 \%$ of German surface water bodies have reached a good ecological status [3]. A main reason for this, certainly, is the intensive use of landscapes in Germany.

The architecture of the WFD acknowledges these difficulties by complementing its ambitious environmental objectives in Art.4.1 with a far-reaching exemption regime. Art. 4.4 allows under certain circumstances the 2015 deadline to be extended by two 6 year periods at maximum. For those water bodies that will not achieve good water status by 2027, member states may strive for "less stringent environmental objectives" if certain conditions are met. Less stringent objectives can be justified for certain water bodies if "they are so affected by human activity [ ... ] or their natural condition is such that the achievement of [a good water status] would be infeasible or disproportionately expensive" (Art. 4.5 WFD, accentuation by the authors).

Article 4(5) is also applicable to artificial or heavily modified water bodies. Concerning these, the WFD's environmental objective are defined as only "a good ecological potential and a good surface water chemical status" rather than the "good surface water status" applied to natural surface water bodies. The argument of this paper is applicable to both. Hence, in the remainder of the paper we generally refer to "good status/potential".

The dilemma is that on the one hand, exemptions are an integral part of the WFD to allow for-also under the holistic perspective of sustainability-necessary utilisation of nature, landscape and resources by mankind. On the other hand, however, an excessive use of exemptions bears the danger of arbitrariness and of "watering down" the WFD's ambitions. To a much greater extent than the term "infeasible", the term "disproportionate" leaves room for interpretation. The way in which the term "disproportionately expensive" is defined and entered into the decisions on which measures for improving water status are actually taken is decisive for effectiveness of the directive, which is the cornerstone of Europe's water policy.

\subsection{Interpretation of Disproportionality}

Throughout Europe, there is as yet no unified and only a few well-established, applicable methodologies for routinely assessing disproportionality (for an overview see [4]). However, the attempts made by the European member states have rarely been published and/or reflected in the scientific literature.

The literal meaning of "disproportionate" is that the costs of achieving good status/potential are out of proportion if compared to a certain benchmark. They could be too high in relation to the positive effects, i.e., the generated utility of the measures (cost-benefit analysis, CBA), or in relation to the financial capacity of the (public or private) subjects that have to bear the costs (affordability) [5].

The interpretation of "disproportionality" in terms of a cost-benefit calculation may seem most obvious at first sight [6]; accordingly, several attempts for an operationalisation have been made along this line [7-11]. However, direct and indirect methods for evaluating the benefits (i.e., ecosystem services) have been found to be very laborious [11] and to face methodological shortcomings [12-15]. In conclusion, the authors consider CBA to be an appropriate method for selected cases only (large cities, exceptionally high economic interests at stake, important employment issues etc.), but not to be suitable 
as a routine methodology for a large number of water bodies [4]. German water authorities also show reservations against any routine application of CBA to assess disproportionality, whereas other EU member states (e.g., the UK and Denmark) are more affine to economic monetisation methods and take CBA as the basis of disproportionality assessments in the context of practical water management.

\subsection{Two Approaches for Assessing Disproportionality}

Accordingly a need to develop alternative methods for assessing disproportionality, which are not exclusively based on CBA but also consider affordability aspects, has been articulated by the German water authorities [16]. Two approaches that address this need will be described, compared and discussed in the following. They are both designed for surface water bodies. The aim of the comparison is elaborate their similarities as well as their specific pros and cons in order to get a feeling for their scope and applicability. Altogether the comparison should show to what extent the two approaches are able to support the German water authorities in answering the question stated in the title of the paper: "Is the achievement of 'good status/potential' for German surface waters disproportionately expensive?"

A first approach-we will call it average cost approach henceforth-was suggested by Ammermüller et al. [17]. Its core idea is based on a ranking of normalised costs for achieving good ecological status/potential in the various surface water bodies. According to this average cost approach, water bodies are considered candidates for disproportionately high costs if their costs are higher than some cost threshold which is determined as a markup of average costs in all water bodies. So, in the average cost approach, costs for achieving good ecological status/potential are potentially considered as being disproportionately high if they are significantly higher than what would be a "relatively normal effort" for reaching the environmental objectives of Art. 4.1 WFD. Based on Ammermüller et al. [17], this approach is refined in this paper to let the markup factor depend on the generated utility (regarding the water body itself and beyond) by bringing the surface water body in question from the current to a good ecological status/potential in a consistent way.

Following the request of practitioners for a method with less data requirements (particularly with respect to the comprehensiveness of cost data), the authors developed a second approach $[4,17]$, which we call benchmark approach. Its core idea is to determine a water-body-specific disproportionality threshold which is then compared to the projected costs of achieving "good status/potential". The derivation of the disproportionality threshold in the benchmark approach takes the past public expenditures on water management as the basis. These expenditures are interpreted as a measure for the financial capacity and the willingness of the state to invest into water protection not only in the past, but also in the future. Normalised data on past public expenditures for water protection over some period of time are, as in the average cost approach, marked up, i.e., multiplied by some factor depending on the generated utility in order to determine the disproportionality threshold specific to the water body.

\subsection{Case Study and Data Set}

Water management in Germany is placed in the responsibility of the German federal states. Both approaches are then applied to a comprehensive data set from one German federal state, containing cost data for the complete set of all 164 surface water bodies in the fields of (i) passability of waters for migrating fish, (ii) morphological improvements, (iii) sewage treatment, and (iv) rainwater retention. Because it contains data for the complete set of water bodies, this data set also opens up the possibility to apply the average cost approach and, hence, to compare these two methods of determining disproportionality.

\subsection{Outline of the Paper}

This paper is structured as follows: Section 2 introduces the benchmark approach by Klauer et al. [4] and Sigel et al. [18] and also refines the average cost approach of Ammermüller 
et al. [17] in such a way that it considers the utility generated by bringing the surface water body in question from the current to a good ecological status/potential in the same consistent way as the benchmark approach. In Section 3, both approaches are applied to a real-world data set from a German federal state. Section 4 discusses the results with respect to both methodological issues and the specific situation in the federal state. Section 5 concludes.

\section{Method: Two Approaches for Assessing Disproportionality of Costs}

Both methods, the benchmark approach developed in $[4,18]$ as well as the average cost approach proposed by Ammermüller et al. [17], assess disproportionality of costs by comparing the projected costs for achieving good status/potential of a given surface water body by 2027 to some sort of cost benchmark which we call disproportionality threshold and which is specific to that water body. If the projected costs are higher than the threshold, then costs are considered to be disproportionately high. The two methods differ, however, in the way the threshold is determined.

Both approaches feature a similar basic outline, with some tasks being the same for the benchmark and the average cost approaches and some tasks differing between them. The following tasks have to be carried out:

- A) Determination of projected costs to achieve good ecological status/potential in the water body at hand (same);

- B) Estimation of the utility generated by bringing the surface water body in question from the current to a good ecological status/potential (same);

- C) Determination of a cost reference, normalised to catchment area, and calculation of the disproportionality threshold specific to the water body at hand (differing);

- D) Assessment of disproportionality by comparison of the projected costs with the disproportionality threshold (same).

\subsection{Determination of Projected Costs to Achieve Good Ecological Status/Potential}

An essential precondition for assessing the disproportionality of costs for any water body is that a programme of measures for this water body has already been worked-out. This programme of measures describes how the environmental objectives (good status/potential) could, in principle, be achieved by 2027 in a cost-effective way [19-23]. It forms the basis for the calculation of projected costs for achieving the environmental objectives for this water body. For this cost calculation, all costs have to be considered that accumulate in the period 2009-2027, which includes costs that have already been spent as well as expected expenditure up until 2027. Considering three WFD management cycles ( $=18$ years) instead of just one ( $=6$ years) ensures that any delay in implementing measures during the early management cycles will not generate the misleading impression of disproportionately high costs in the last cycle. In principle, all kinds of costs need to be considered, including investment and operating costs as well as personnel and administrative costs. However, only the costs of "supplementary measures" according to Article 11(4) WFD are to be taken into account. The cost of "basic measures" according to Article 11(3) WFD aimed at meeting the "minimum requirements" for water protection must not be included, because Member States are obliged to implement them in any case, i.e., independently of the WFD [24].

Step A has to be carried out in both the benchmark and the average cost approach. In the latter, however, this step has to be carried out for all water bodies, not just the one for which (dis-)proportionality is assessed.

\subsection{Estimation of Generated Utility}

The planned measures for reaching the WFD's environmental objectives entail basically two types of benefits: (i) water-related benefits generated by improving the quality of the surface water body in question from its current status to good status/potential and (ii) so-called "additional benefits" 
(e.g., for tourism) as we will explain below. Both types of benefits are not measured in monetary terms but estimated in a semi-quantitative way.

\subsubsection{Determination of the Current-State-to-Target Distance of the Water Body}

The "current-state-to-target distance" is a proxy for the first type of benefits. It is defined as the difference between the current status of the water body and the environmental objective of a good ecological status/potential. However, the procedure can easily been extended (mutatis mutandis) to include the chemical status as well.). The data for its calculation can be taken from the evaluation of the water body according to WFD monitoring (Art. 8 and Annex V). As described in [24] the following five quality components are considered: "Macrozoobenthos", "Macrophytes", "Phytoplankton", "Fish", and "Environmental quality norm" (EQN). Regarding the four ecological quality components, the current-state-to-target distance can take on the following values: $0=$ good or very good current status/potential (objective has been met already), $1=$ moderate, $2=$ poor, $3=\mathrm{bad}$. With respect to the quality component "environmental quality norm" (EQN), only two values are possible: $0=\mathrm{EQN}$ achieved, $3=$ EQN failed. The overall current-state-to-target distance is defined as the mean derived from the current-state-to-target distances of the four ecological quality components and the environmental quality norm.

At this point our approach differs from the "one out all out principle" of the WFD, according to which the component with the worst results determines the overall rating for the water body. This is because we use the quality assessment as proxy data for utility generated by achieving the environmental objective.

The WFD's central environmental goal of a good water status (Art. 4.1) is compounded of a good ecological status and a good chemical status (Annex V). Our proposed procedure to measure the current state to target distance, however, only refers to the good ecological status/potential, while the good chemical status is neglected. The reason is that at the moment $100 \%$ of German water bodies are in a bad chemical status due to Germany-wide mercury contamination [3]. Moreover, there is a debate on how to improve and refine the monitoring as well as the assessment of the chemical status [25].

\subsubsection{Determination of the Additional Benefits}

The implementation of the planned measures not only improves the water status of the water body in terms of the WFD but might also have additional positive side-effects, so-called "additional benefits" $[17,24]$. Additional benefits $(\mathrm{AB})$ are considered within the following five categories:

- Terrestrial ecology and nature protection-e.g., provision or improvement of habitats, green corridors and linking of habitats.

- Drinking water supply and purification-e.g., increased quantity and/or quality of raw water for drinking water provision.

- Flood protection-e.g., improved retention potential of flood plains, reduced flow velocity.

- Soil protection-e.g., reduced erosion and sediment entry into waters, reduced loss of soil fertility, less sand-filling of water-retaining structures.

- Tourism, recreation, cultural heritage, aesthetics—e.g., improved attractiveness of landscape for tourism and recreation.

In principle the additional benefits of measures at a certain water body may have (positive) effects outside of the catchment area which nevertheless should also be taken into consideration.

Following Klauer et al. [24], we propose that the assessment of additional benefits is done by experts in a largely non-formal way on the basis of their local knowledge and expertise. The experts distribute benefit scores between 0 and 3 for each of the five categories in the following manner: $0=$ no additional benefits, $1=$ low, $2=$ medium, $3=$ high additional benefits. The assessment should take into account both the extent (quantity, intensity) of the positive side effects and their relevance (e.g., number of people affected, affected area, substitutability, etc.). The additional benefits are first 
assessed for each benefit category separately. The aggregated additional benefit is then calculated as the mean derived from the separate benefits for the five benefit categories.

Both categories of generated utility will be entered into the determination of the disproportionality threshold in Step C: the higher the utility generated by improving water status, the higher the costs that are considered proportional.

\subsection{Determination of Cost Reference and Disproportionality Threshold}

\subsubsection{The Benchmark Approach}

In the benchmark approach (for a more detailed description see [4], the starting point for the calculation of a water-body-specific disproportionality threshold is past national public expenditure on water protection. In Germany, an estimation of this expenditure is possible using official statistics. These data are available in annual reports on public budget spending by the Federal Statistical Office, assuming that water protection is described by the statistical categories "sewage treatment" (Abwasserbeseitigung) and "water and land management" (Wasserwirtschaft und Kulturbau). Evaluating the period from 1992 to 2009, prior to the start of the first WFD planning cycle, we find that an average of 9080 million $€$ (measured according to 2010 prices) was spent each year on water protection in Germany. Related to the total area of Germany $\left(357,167 \mathrm{~km}^{2}\right)$, the normalised average expenditure was $25,422 € /\left(\mathrm{km}^{2}\right.$.year). The national average for past public expenditure on water protection is scaled to the catchment area of the water body in question by multiplying the average of $25,422 € /\left(\mathrm{km}^{2}\right.$.year $)$ by the catchment area of the water body. The result is a figure for past annual public expenditure on water protection normalised to the size of the water body at hand.

This, however, is not yet the disproportionality threshold: the latter is defined by the normalised past expenditure multiplied by a so-called effort factor. This effort factor is an expression of the additional effort considered to be appropriate to achieve the new and ambitious objectives of the WFD. It is determined as a linearly increasing function of the current-state-to-target distance and the additional benefits (Step B) and is 0 for vanishing generated utility (both current-state-to-target distance and the additional benefits are 0 ). That is, if the water body has (nearly) achieved the Directive's environmental objectives AND if there are no additional benefits, then (almost) no further management measures are necessary and, hence, any (considerable) additional costs will be disproportionate [4]. Acknowledging that this inherently is a political decision, for reasons of plausibility propose to weigh the current-state-to-target distance twice as high the additional benefits and to limit the effort factor to a maximum of 0.5 . The proposed value 0.5 cannot be justified scientifically. Rather it is a reasonable suggestion which has been developed in consultation with practitioners [4]. In line with these considerations, the effort factor is calculated as:

$$
\text { effort factor }=\frac{2}{18} \text { current-state-to-target distance }+\frac{1}{18} \text { additional benefits }
$$

The water-body-specific disproportionality threshold with respect to the 18 -year time period is calculated as:

disproportionality threshold

$=$ normalised annual past public expenditure $\times \mathrm{WB}$ area $\times$ effort factor $\times 18$ years

where "WB area" indicates the area of the water body catchment.

\subsubsection{The Average Cost Approach}

The average cost approach put forward here is, with enhancements, based on [17]. The approach bases the disproportionality threshold for any given surface water body on the projected costs to achieve good status/potential in all other water bodies in the federal state (Step A). These costs are normalised with respect to the catchment area of the water body and the state-wide average is 
determined. The disproportionality threshold is then derived by multiplying the normalised average costs with a spreading factor which depends on the utility generated by bringing the surface water body in question from the current to a good ecological status/potential (Step B). The spreading factor expresses how much the (normalised) costs of achieving good status/potential in the water body at hand may at maximum deviate from average before they are considered to be disproportionately high. We propose that the calculation of the spreading factor and, hence, the disproportionality threshold should take into account the following conditions:

The maximum spreading factor should be three, i.e., the highest possible disproportionality threshold is the threefold of the average. As in the benchmark approach (Section 2.3.1), it has to be noted that this decision on the maximum threshold is an inherently political decision. This maximum markup against average costs of three may seem quite high at first glance and, specifically, if compared to the maximum effort factor of 0.5 in the benchmark approach. However, in the benchmark approach, the effort factor expresses an effort for achieving good water status that is additional to the expenditure for basic measures (cf. Section 2.1). Here, in the average cost approach, differing additional expenditures for supplementary measures are compared across different water bodies.

If the current-state-to-target distance is zero, i.e., the water body is already in a good status/potential, and if there are no additional benefits then the threshold should also be zero. In other words, any effort would be disproportionate.

The spread factor is, for reasons of simplicity, assumed to be a linear function of the two types of benefits, i.e., the current-state-to-target distance and the additional benefits, whereby the former is given double weight compared to the latter (as in the benchmark approach, cf. Section 2.3.1).

In short, the spreading factor is calculated as:

$$
\text { spreading factor }=\left(\frac{2}{3} \text { current-state-to-target distance }+\frac{1}{3} \text { additional benefits }\right)
$$

The disproportionality threshold for the 18 -year period for the water body at hand is then:

$$
\begin{aligned}
& \text { disproportionality threshold } \\
& =\text { normalised average costs } \times \text { WB area } \times \text { spreading factor } \times 18 \text { years }
\end{aligned}
$$

Effectively, the water bodies which are the most expensive in relation to size and generated utility are then classified as being disproportionately expensive. This method is, however, only applicable if projected cost data are available for all water bodies in the domain of the responsible water authority.

\subsection{Assessment of Disproportionality}

In the final, small step, the water-body-specific costs of achieving the objective of a good status/potential, as calculated in Step A, are compared to the water-body-specific disproportionality threshold calculated in Step C. If the threshold is exceeded, the costs are disproportionately high and less stringent environmental objectives might be justified.

To sum up: the significant difference between the two approaches is the basis and the calculation of the disproportionality threshold. The other elements of the assessment are equivalent between the benchmark and the average cost approach.

\section{Results of the Empirical Application of Both Approaches}

In this section, both approaches-the benchmark approach as well as the average cost approach-are empirically applied, tested and compared on data from a German federal state, comprising cost data for all of its 164 surface water bodies. For the sake of a step-by-step demonstration of the two approaches, we identified four example water bodies, called WB 1-4 henceforth. They were selected to give an overview of different situations in the area of the federal state (see Table 1). 
Table 1. Example water bodies.

\begin{tabular}{ccccc}
\hline Short Name & Characterisation & Area $\left[\mathbf{k m}^{2}\right]$ & $\begin{array}{c}\text { Length of River } \\
\text { Section }[\mathbf{k m}]\end{array}$ & $\begin{array}{c}\text { Citizens in the } \\
\text { Water Body Area }\end{array}$ \\
\hline WB 1 & Upper section of a river & 250 & 116 & 45,066 \\
WB 2 & Section of a river & 18 & 6 & 13,986 \\
WB 3 & Section of a larger stream & 30.4 & 37 & 5340 \\
WB 4 & River flowing into a larger stream & 101 & 41 & 113,942 \\
\hline
\end{tabular}

\subsection{Results of Step A "Determination of Projected Costs to Achieve Good Ecological Status/Potential"}

The competent authorities made considerable planning efforts. In order to reach a good status/potential, they set up lists of measures in the fields of (i) passability of waters for migrating fish; (ii) morphological improvements; (iii) sewage treatment; and (iv) rainwater retention. It might be that additional measures in other fields, namely in agriculture, would be necessary, e.g., in order to prevent diffuse pollution by nutrients. However, concerning the agricultural sector, no reliable cost estimates are currently available for considered federal state (and elsewhere in Germany). Therefore, the cost figures must be seen as a conservative estimate of the costs to achieve a good ecological status/potential. Following the argument in Section 2.1, only the costs for additional measures can be taken into account for assessing the disproportionality of costs.

Table 2 gives an overview of measures, their (real or projected) costs and the total costs normalised per year and $\mathrm{km}^{2}$. Figure 1 shows the cost of measures for reaching a good status/potential in all water bodies in the considered federal state, ranked according to normalised costs $\left(€ / \mathrm{km}^{2}\right.$.year). The normalised costs for the vast majority of water is below $10,000 € /\left(\mathrm{km}^{2} \cdot\right.$ year $)$. It is apparent, however, that for a few water bodies the normalised costs are significantly higher, up to $75,500 € /\left(\mathrm{km}^{2}\right.$.year $)$. Note that the pure ranking of normalised costs is not sufficient to determine disproportionality according to any of the two approaches.

Table 2. (Real or projected) costs for reaching good ecological status/potential in the example water bodies (Source: Own calculation based on data provided by Environmental Ministry of the federal state).

\begin{tabular}{|c|c|c|c|c|}
\hline Short Name & Projected or Realised Measures & $\begin{array}{c}\text { Costs } \\
{[\mathbf{k} €]}\end{array}$ & $\begin{array}{c}\text { Total Costs } \\
\text { 2009-2027 [k€] }\end{array}$ & $\begin{array}{c}\text { Normalised Costs } \\
{\left[€ /\left(\mathrm{km}^{2} \cdot \text { Year }\right)\right]}\end{array}$ \\
\hline \multirow{4}{*}{ WB 1} & Achieve passability f. migrating fish & 2085 & & \multirow{4}{*}{641} \\
\hline & Improve hydro-morphology & - & & \\
\hline & Enhance sewage treatment & 120 & & \\
\hline & Rainwater retention & 678 & 2883 & \\
\hline \multirow{4}{*}{ WB 2} & Achieve passability f. migrating fish & 650 & & \multirow{4}{*}{1970} \\
\hline & Improve hydro-morphology & - & & \\
\hline & Enhance sewage treatment & - & & \\
\hline & Rainwater retention & - & 650 & \\
\hline \multirow{4}{*}{ WB 3} & Achieve passability f. migrating fish & 800 & & \multirow{4}{*}{2923} \\
\hline & Improve hydro-morphology & 796 & & \\
\hline & Enhance sewage treatment & 5 & & \\
\hline & Rainwater retention & - & 1601 & \\
\hline \multirow{4}{*}{ WB 4} & Achieve passability f. migrating fish & 1940 & & \multirow{4}{*}{12,033} \\
\hline & Improve hydro-morphology & 13,730 & & \\
\hline & Enhance sewage treatment & - & & \\
\hline & Rainwater retention & 6199 & 21,869 & \\
\hline
\end{tabular}




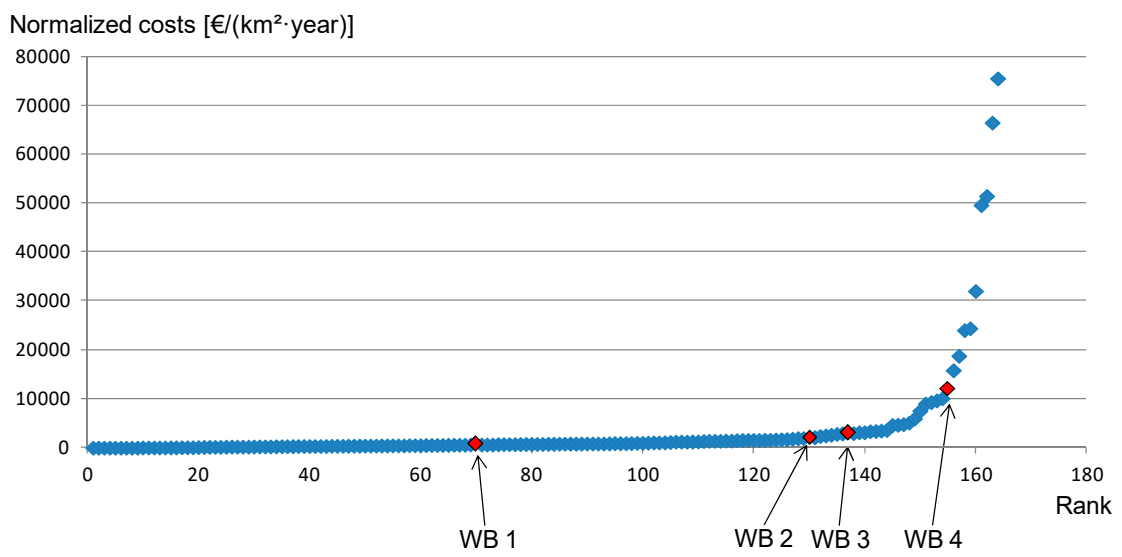

Figure 1. Ranking of normalised costs in $€ /\left(\mathrm{km}^{2}\right.$.year) of measures for reaching a good status/potential. With costs of $641 € /\left(\mathrm{km}^{2} \cdot\right.$ year $)$ water body $(\mathrm{WB}) 1$ reaches rank 70 , with $1970 € /\left(\mathrm{km}^{2} \cdot\right.$ year $)$ WB 2 reaches rank 129, with $2.923 € /\left(\mathrm{km}^{2}\right.$.year) WB 3 reaches rank 137 , and with costs of $12,033 € /\left(\mathrm{km}^{2} \cdot\right.$ year $)$ WB 4 reaches rank 155. (Source: Own calculation based on data provided by Environmental Ministry of the federal state).

\subsection{Results of Step B "Estimation of Generated Utility"}

\subsubsection{Current-State-to-Target Distance}

For the calculation of the current-state-to-target distance, the recent results of the monitoring (according to WFD Art. 8 and Annex V) in the considered federal state have been used. Table 3 summarises the monitoring results for the four example water bodies: for all quality components, the current status (in verbal expression) and the resulting component-based status to target distance is given (in numerical expression). The last column lists the overall current-state-to-target distance, calculated as mean over all applicable component distances.

Table 3. The ecological status of example water bodies WB 1-4 according to 2014 Water Framework Directive (WFD) monitoring results and the corresponding current-state-to-distance values (Source: data provided by Environmental Ministry of the federal state, own calculations).

\begin{tabular}{ccccccc}
\hline $\begin{array}{c}\text { Short } \\
\text { Name }\end{array}$ & $\begin{array}{c}\text { Macrophytes/ } \\
\text { Phytobentos }\end{array}$ & $\begin{array}{c}\text { Macrozoo- } \\
\text { Benthos }\end{array}$ & Phytoplankton & Fish & EQN & $\begin{array}{c}\text { Current-State-to- } \\
\text { Target Distance }\end{array}$ \\
\hline WB 1 & 1 (moderate) & 0 (good) & not relevant & 1 (moderate) & 0 (achieved) & 0.5 \\
WB 2 & 1 (moderate) & 1 (moderate) & not relevant & 1 (moderate) & 0 (achieved) & 0.75 \\
WB 3 & 0 (good) & 1 (moderate) & not relevant & 1 (moderate) & 0 (achieved) & 0.5 \\
WB 4 & 1 (moderate) & 2 (poor) & not relevant & 2 (poor) & 3 (not achieved) & 2.0 \\
\hline
\end{tabular}

Notes: ${ }^{1}$ The component "phytoplankton" of the ecological status is according to the WFD's evaluation system not relevant for all water body types and therefore not monitored in all cases.

With respect to all 164 surface water bodies, the minimum current-state-to-target distance is 0 (i.e., good status/potential is already reached), the maximum is 2.25 , and the average is 0.74 .

\subsubsection{Additional Benefits}

It has been suggested in Section 2.2.1 that the assessment of additional benefits is done by experts in a largely non-formal way. While the authorities of the federal state signalised that principally they would be able and willing to undertake such an expert assessment, they were-due to time and capacity restrictions-not yet able to provide the respective results for our case study. For this reason, we explore the two hypothetical cases in which (a) the additional benefits $(\mathrm{AB})$ in all water bodies are at maximum ( $=3$ ) and in which (b) there are no additional benefits $(=0)$, and calculate disproportionality thresholds for both of these hypothetical cases. 


\subsection{Results of Step C "Determination of Cost Reference and Disproportionality Threshold"}

After assessing the utility generated by the management measures for bringing the water bodies to a good water status/potential, the disproportionality thresholds can be determined following either the benchmark approach (Section 2.3.1) or the average cost approach (Section 2.3.2). Again, we demonstrate calculations and results on the four example water bodies WB 1-4.

\subsubsection{Benchmark Approach}

Using the results of Step B (Section 3.2) and following Section 2.3.1, the effort factor and disproportionality thresholds can be calculated (Table 4). The column "normalised past expenditure $x$ effort factor" is helpful to illustrate the effect of the generated utility within the water bodies on potential disproportionality, because it is normalised to one $\mathrm{km}^{2}$ and year. The disproportionality threshold, however, relates to the time span of 18 years (i.e., the first three management cycles) and depends on the area of the water body's catchment.

The value "normalised past expenditure $\times$ effort factor" (for Germany) maximally ranges between $0 € /\left(\mathrm{km}^{2}\right.$.year) (current-state-to-target distance $=0$ and additional benefits $\left.=0\right)$ and $12,711 € /\left(\mathrm{km}^{2} \cdot\right.$ year) (current-state-to-target distance $=3$ and additional benefits $=3$ ).

Table 4. Effort factor and disproportionality threshold for example water bodies WB 1-4 and the two hypothetical cases of zero additional benefit and maximum additional benefit. (Source: own calculations).

\begin{tabular}{|c|c|c|c|c|c|c|c|}
\hline \multirow[t]{2}{*}{$\begin{array}{l}\text { Short } \\
\text { Name }\end{array}$} & \multirow[t]{2}{*}{$\begin{array}{l}\text { Current-State-to- } \\
\text { Target Distance }\end{array}$} & \multicolumn{2}{|c|}{ Effort Factor cf. (1) } & \multicolumn{2}{|c|}{$\begin{array}{c}\text { Normalised Past } \\
\text { Expenditure } \times \text { Effort } \\
\text { Factor }\left[€ /\left(\mathrm{km}^{2} \cdot \text { Year }\right)\right]\end{array}$} & \multicolumn{2}{|c|}{$\begin{array}{c}\text { Disproportionality } \\
\text { Threshold [k€] } \\
\text { cf. (2) }\end{array}$} \\
\hline & & $\mathrm{AB}=0$ & $\mathrm{AB}=3$ & $\mathrm{AB}=0$ & $\mathrm{AB}=3$ & $\mathrm{AB}=0$ & $\mathrm{AB}=3$ \\
\hline WB 1 & 0.5 & 0.06 & 0.22 & 1412 & 5649 & 6349 & 25,395 \\
\hline WB 2 & 0.75 & 0.08 & 0.25 & 2118 & 6355 & 699 & 2097 \\
\hline WB 3 & 0.5 & 0.06 & 0.22 & 1412 & 5649 & 774 & 3094 \\
\hline WB 4 & 2.0 & 0.22 & 0.39 & 5649 & 9886 & 10,269 & 17,968 \\
\hline
\end{tabular}

It can be seen that the extent of additional benefits influences the disproportionality threshold considerably.

\subsubsection{Average Cost Approach}

Following Section 2.3.2, the (real or projected) normalised average costs to achieve good status/potential of all surface water bodies in the federal state have to be assessed. These costs are normalised with respect to the catchment area of the water body and the state-wide average is determined. For the considered federal state, the normalised average costs are $3643 € /\left(\mathrm{km}^{2}\right.$.year). Using the results of Step B (Section 3.2), the spreading factor and disproportionality thresholds can be calculated (Table 5). The column "normalised average cost $\times$ spreading factor" is helpful to illustrate the effect of the generated utility within the water bodies on potential disproportionality, because it is normalised to one $\mathrm{km}^{2}$ and year.

The value "normalised average costs $\times$ spreading factor" maximally ranges between $0 € /\left(\mathrm{km}^{2}\right.$.year) (current-state-to-target distance $=0$ and additional benefits $\left.=0\right)$ and $10,930 € /\left(\mathrm{km}^{2} \cdot\right.$ year) (current-state-to-target distance $=3$ and additional benefits $=3$ ). 
Table 5. Spreading factor and disproportionality threshold for example water bodies WB 1-4 and the two hypothetical cases of zero additional benefit and maximum additional benefit. (Source: own calculations).

\begin{tabular}{|c|c|c|c|c|c|c|c|}
\hline \multirow[t]{2}{*}{$\begin{array}{l}\text { Short } \\
\text { Name }\end{array}$} & \multirow[t]{2}{*}{$\begin{array}{l}\text { Current-State-to- } \\
\text { Target Distance }\end{array}$} & \multicolumn{2}{|c|}{$\begin{array}{l}\text { Spreading Factor } \\
\text { cf. (3) }\end{array}$} & \multicolumn{2}{|c|}{$\begin{array}{l}\text { Normalised Average } \\
\text { Costs } \times \text { Spreading } \\
\text { Factor }\left[€ /\left(\mathrm{km}^{2} \cdot \text { Year }\right)\right]\end{array}$} & \multicolumn{2}{|c|}{$\begin{array}{c}\text { Disproportionality } \\
\text { Threshold [k€] } \\
\text { cf. (4) }\end{array}$} \\
\hline & & $\mathrm{AB}=0$ & $\mathrm{AB}=3$ & $\mathrm{AB}=0$ & $\mathrm{AB}=3$ & $\mathrm{AB}=0$ & $\mathrm{AB}=3$ \\
\hline WB 1 & 0.5 & 0.33 & 1.33 & 1214 & 4857 & 5459 & 21,836 \\
\hline WB 2 & 0.75 & 0.5 & 1.5 & 1822 & 5465 & 601 & 1803 \\
\hline WB 3 & 0.5 & 0.33 & 1.33 & 1214 & 4857 & 665 & 2661 \\
\hline WB 4 & 2.0 & 1.33 & 2.33 & 4858 & 8501 & 8829 & 15,450 \\
\hline
\end{tabular}

Also for the average cost approach, the extent of additional benefits influences the disproportionality threshold greatly.

\subsection{Results of Step D}

Table 6 summarises the cost data for the four example water bodies WB 1-4 and contrasts it to the water-body-specific disproportionality thresholds. These thresholds are calculated for the two hypothetical and extreme cases of zero $(\mathrm{AB}=0)$ and maximum $(\mathrm{AB}=3)$ additional benefit, using the benchmark as well as average cost approaches.

Table 6. Comparison of (real and projected) costs for reaching the good status/potential in example water bodies WB 1-4 for two hypothetical cases of no additional benefits $(A B=0)$ and maximum additional benefits $(\mathrm{AB}=3)$ using the benchmarking approach as well as the average cost approach. Orange shade indicates disproportionality and green proportionality. (Source: own calculations).

\begin{tabular}{|c|c|c|c|c|c|c|c|}
\hline \multirow[t]{2}{*}{$\begin{array}{l}\text { Short } \\
\text { Name }\end{array}$} & \multirow[t]{2}{*}{$\begin{array}{l}\text { Current-State-to- } \\
\text { Target Distance }\end{array}$} & \multirow[t]{2}{*}{$\begin{array}{l}\text { Normalised } \\
\text { Costs } \\
{\left[€ /\left(\mathrm{km}^{2} \cdot \text { Year }\right)\right]}\end{array}$} & \multirow[t]{2}{*}{$\begin{array}{l}\text { Costs } \\
\text { 2009-2027 } \\
{[k €]}\end{array}$} & \multicolumn{2}{|c|}{$\begin{array}{c}\text { Disproportionality } \\
\text { Threshold [k€] } \\
\text { Benchmark Approach }\end{array}$} & \multicolumn{2}{|c|}{$\begin{array}{c}\text { Disproportionality } \\
\text { Threshold [k€] } \\
\text { Average Cost Approach }\end{array}$} \\
\hline & & & & $\mathrm{AB}=0$ & $\mathrm{AB}=3$ & $\mathrm{AB}=0$ & $\mathrm{AB}=3$ \\
\hline WB 1 & 0.5 & 641 & 2883 & 6349 & 25,395 & 5459 & 21,836 \\
\hline WB 2 & 0.75 & 1970 & 650 & 699 & 2097 & 601 & 1803 \\
\hline WB 3 & 0.5 & 2900 & 1601 & 774 & 3094 & 665 & 2661 \\
\hline WB 4 & 2.0 & 12,033 & 21,869 & 10,269 & 17,968 & 8829 & 15,450 \\
\hline
\end{tabular}

Table 6 shows that for the data set, calculated disproportionality thresholds following the benchmark and the average cost approaches are very similar but not identical. It is apparent that the ranking of normalised costs (i.e., per annum and per $\mathrm{km}^{2}$ ) in Figure 1 provides a first hint towards disproportionality: the further to the right a water body is situated in Figure 1 the more likely the costs are assessed to be disproportionate. Water body 4 shows a clear indication. Irrespective of the assumption about additional benefits generated by bringing this water body into good ecological status/potential, costs are assessed to be disproportionately high.

So far, we have focused on four example water bodies. Now we regard the totality of water bodies in the considered federal state. As we have seen for the example water bodies, the data on the generated additional benefit is decisive for the question of disproportionality. Table 7 summarises the results of the disproportionality assessment for the bulk of 164 surface water bodies of the federal state. 
Table 7. Number of water bodies where disproportionality is indicated using the benchmarking approach as well as the average cost approach, assuming no additional benefits $(A B=0)$ in all water bodies (case 1 ) or maximum additional benefits $(A B=3)$ in all water bodies (case 2$)$ (Source: own calculations).

\begin{tabular}{ccc}
\hline $\begin{array}{c}\text { Overview of All Water Bodies }(\boldsymbol{n}=\mathbf{1 6 4 )} \\
\text { Number of Water Bodies Where } \\
\text { Disproportionality of Costs as Indicated by: }\end{array}$ & $\begin{array}{c}\text { Case 1: No } \\
\text { Additional } \\
\text { Benefits }(\mathbf{A B}=\mathbf{0})\end{array}$ & $\begin{array}{c}\text { Case 2: Maximum } \\
\text { Additional Benefits } \\
(\mathbf{A B}=\mathbf{3})\end{array}$ \\
\hline Benchmarking approach & 47 & 15 \\
Average cost approach & 52 & 15 \\
Both approaches & 47 & 15 \\
\hline
\end{tabular}

It can be seen that the assessment of generated utility, in particular additional benefits, plays an important role discriminating between water bodies with and without disproportionally high costs. While the differences in the number of disproportionally expensive water bodies between the two cases of $\mathrm{AB}=0$ and $\mathrm{AB}=3$ show that both the benchmark and average cost approaches are sensitive to the generated utility, the absolute numbers are less resilient: they directly depend on the parameters in Equations (1) and (3) and can, hence, only be judged to be plausible or implausible.

\section{Discussion}

The notion of disproportionality intrinsically includes value judgments (Klauer et al. [4] with reference to $[26,27])$. Hence, it is not possible to determine objectively and a priori which cost level is proportionate or disproportionate. The only benchmark which is less prone to these value judgments and sometimes claimed to be more "objective" would be the benefits in a full-blown cost-benefit calculation. However, due to the significant methodological shortcomings of CBA (see above) as well as its high complexity and effort required, this is not a realistic option for routine application to a high number of water bodies. Interestingly, the WFD itself refrains from using CBA to determine its environmental objectives in the first place, but instead bases these on a natural reference state without cost-benefit considerations.

This implies that a test of the methodologies described above cannot prove them as being "right" or "wrong" or as being "accurate" or "inaccurate", on a fundamental level, because there is no "objective" benchmark. However, it can be argued on the level of applicability and plausibility, whether or not such a methodology is appropriate. They can be seen as a useful heuristics (sensu [26]) that is able to support the competent authorities when making their value judgments on disproportionality. On this level, our comparative test finds both methods to be appropriate. Very relevant for this conclusion is the fact that both methods can be applied, and successfully discriminate between water bodies with and without disproportionately high costs. The results are intuitive and both methods yield very similar results.

However, both approaches can be questioned and have already been questioned in discussions with practitioners. The benchmark approach has been criticised for "comparing apples with oranges", because past expenditure on water management averaged over all of Germany does not take account of regional conditions and also includes duties beyond implementation of WFD. While the authors acknowledge these problems, we argue that this benchmark can still give an overall feeling of the amount of money a society is able and willing to spend on water management. Regional conditions, e.g., differences between different federal states, can be acknowledged by varying coefficients in the calculation of the effort factor (1). The average cost approach is based on assessing and judging the heterogeneity of water bodies within a federal state. In addition to its high data requirements, a limitation of this approach is that there is no absolute exogenous benchmark for assessing disproportionality. Hence, in every federal state the relatively most costly water bodies are prone to be classified as disproportionate, regardless of absolute costs. 
Finally, the authors want to stress again that both approaches for assessing disproportionality are designed for a standardised application to a wide range of water bodies. In specific cases, in which the averaging approaches of these methods are not appropriate, this methodology is at risks of delivering non-plausible results. Considering Figure 1 for example, water bodies with higher costs than WB 4 are declared disproportionate regardless of any utility considerations because normalised costs exceed three times normalised average costs (3643€/ $\mathrm{km}^{2}$.year-cf. Section 3.3.2). In these cases, a more detailed cost-benefit consideration may be appropriate.

\section{Conclusions}

The ambitious Europe-wide environmental objective of a good status-a status close to pristine rivers-is extremely difficult to reach in landscapes that have been intensively used and modified for centuries. The WFD wisely allows for exemptions from its central environmental objective, but it requests a transparent and convincing justification for these cases. Disproportionality of costs would be one acceptable justification. There is an urgent need for methods to check a large number of water bodies that are prospectively failing the good status/potential and to assess whether or not the projected costs of reaching the objective would be disproportionately expensive.

Two different but related approaches have been presented here. The main difference between the two approaches is that they use a different basis for comparison. The benchmark approach takes the past public expenditures on water management as a basis for comparison. It compares the current effort invested in the implementation of the WFD with the money that was, on average, spent for reaching the water management goals in the time before the WFD. The average cost approach, in contrast, compares the effort for one water body with the average costs of all other water bodies.

The empirical tests with extensive and up-to-date data from one German federal state indicate that both approaches yield comparable results and are suitable to support authorities. In order to use disproportionate costs as a justification for exemptions, the European member states need to conduct a substantial planning effort in advance. They need to know which measures would be necessary in order to reach a good status/potential in a cost-efficient way, and how expensive they are [19-21]. The limited availability of reliable cost data has been a considerable problem for the German federal states in the past few years. The federal state that gave us the data for the case study is now the first German state that is able to provide reliable cost data for all of its water bodies, which is a precondition for the average cost approach. The data necessary to calculate the cost thresholds with the benchmarking approach stem mainly from the environmental-economic accounting of the German Federal Statistic Office and the monitoring program which is mandatory according to the WFD. Hence, these data are routinely available. Due to the advancing implementation process of the WFD, cost data will eventually become available more easily. The continuous work on more significant river-basin management plans and programmes of measures leads to better information about how much it would cost to reach a good water status/potential in each case.

All things considered it can be recorded that both approaches are able to support the German water authorities in sorting out those surface water bodies that will most likely not qualify for being disproportionately expensive and in getting an overview over the candidates for disproportionality exemptions. However, for the latter it needs to be checked case by case whether or not certain circumstances or higher-level considerations anyhow justify higher costs in the specific water body.

Acknowledgments: The authors would like to thank our colleagues Moritz Reese, Christine Wolf as well as the members of the advisory board of the project "Unverhältnismäßige Kosten nach EG-Wasserrahmenrichtlinie: Praxistest des Neuen Leipziger Ansatzes (NLA) zur Begründung weniger strenger Umweltziele" commissioned by the "German Working Group on water issues of the Federal States and the Federal Government" (LAWA) for fruitful and critical discussions and helpful comments. Financial support by the German federal states within the "Länderfinanzierungsprogramm 'Wasser, Boden und Abfall' 2016" is gratefully acknowledged. All opinions expressed (and any errors made) in this article are solely those of the authors. 
Author Contributions: Bernd Klauer, Johannes Schiller and Katja Sigel conceived and designed the refinements of the average cost and the benchmark approach as well as the comparison between both. Katja Sigel and Bernd Klauer analyzed the data; Bernd Klauer and Johannes Schiller wrote the paper.

Conflicts of Interest: The authors declare no conflict of interest. The founding sponsors provided the data and obliged the authors not to use the name of the federal state where the data originate from as well as the names of the example water bodies. They had no role in the design of the study; in the analyses, or interpretation of data; in the writing of the manuscript, and in the decision to publish the results.

\section{References}

1. Blackbourn, D. The Conquest of Nature: Water, Landscape, and the Making of Modern Germany; Jonathan Cape: London, UK, 2006.

2. Von Keitz, S.; Dehnhardt, A.; Klauer, B.; Scholz, M. Kapitel 8. Ökosystemleistungen von Gewässern und Auen. In Naturkapital Deutschland-TEEB DE, Ökosystemleistungen in Ländlichen Räumen-Grundlage für Menschliches Wohlergehen und Nachhaltige Wirtschaftliche Entwicklung; von Haaren, C., Albert, C., Eds.; Leibniz Universität Hannover, Helmholtz-Zentrum für Umweltforschung_UFZ: Hannover, Leipzig, 2016; pp. 206-239. Available online: http://www.naturkapital-teeb.de/fileadmin/Downloads/Projekteigene_ Publikationen/TEEB_Broschueren/TEEB_DE_Landbericht_Langfassung.pdf (accessed on 24 July 2017). (In German)

3. German Environmental Agency (UBA). Water Framework Directive. The Status of German Waters 2015; UBA: Bonn, Germany, 2016.

4. Klauer, B.; Sigel, K.; Schiller, J. Disproportionate costs in the EU Water Framework Directive-How to justify less stringent environmental objectives. Environ. Sci. Policy 2016, 59, 10-17. [CrossRef]

5. Klauer, B.; Mewes, M.; Sigel, K.; Unnerstall, H.; Görlach, B.; Bräuer, I.; Pielen, B.; Holländer, R. Verhältnismäßigkeit der Maßnahmenkosten im Sinne der EG-Wasserrahmenrichtlinie-Komplementäre Kriterien zur Kosten-Nutzen-Analyse; UFZ-Bericht 02/2007; Helmholtz Centre for Environmental Research-UFZ: Leipzig, Germany, 2007. (In German)

6. Martin-Ortega, J. Economic prescription and policy applications in the implementation of the European Water Framework Directive. Environ. Sci. Policy 2012, 24, 83-91. [CrossRef]

7. Postle, M.; Fenn, T.; Foottit, A.; Salado, R. CEA and Developing a Methodology for Assessing Disproportionate Costs. In Final Report for Department for Environment, Food and Rural Affairs (Defra), Welsh Assembly Government (WAG), Scottish Executive (SE) and Department of the Environment in Northern Ireland (DOENI); Risk \& Policy Analysts Limited (RPA): Norfolk, UK, 2004.

8. Molinos-Senante, M.; Hernández-Sancho, F.; Sala-Garrido, R. Assessing disproportionate costs to achieve good ecological status of water bodies in a Mediterranean river basin. J. Environ. Monit. 2011, 13, $2091-2101$. [CrossRef] [PubMed]

9. Vinten, A.J.A.; Martin-Ortega, J.; Glenk, K.; Booth, P.; Balana, B.B.; MacLeod, M.; Lago, M.; Moran, D.; Jones, M. Application of the WFD cost proportionality principle to diffuse pollution mitigation: A case study for Scottish Lochs. J. Environ. Manag. 2012, 97, 28-37. [CrossRef] [PubMed]

10. Jensen, C.L.; Jacobsen, B.H.; Olsen, S.B.; Dubgaard, A.; Hasler, B. A practical CBA-based screening procedure for identification of river basins where the costs of fulfilling the WFD requirements may be disproportionate-Applied to the case of Denmark. J. Environ. Econ. Policy 2013, 2, 164-200. [CrossRef]

11. Hecht, D.; Karl, H.; Werbeck, N.; Ebben, T. WRRL an der Unteren Wupper-Untersuchung der Handlungsspielräume und der Erreichbarkeit der Ziele der WRRL an der Unteren Wupper im Rahmen einer Kosten-Nutzen-Analyse am Beispiel der Wärmebelastung; Projektbericht; Wupperverband: Wuppertal, Germany, 2014. (In German)

12. Spash, C.L.; Vatn, A. Transferring environmental value estimates: Issues and alternatives. Ecol. Econ. 2006, 60, 379-388. [CrossRef]

13. Wegner, G.; Pascual, U. Cost-benefit analysis in the context of ecosystem services for human well-being: A multidisciplinary critique. Glob. Environ. Chang. 2011, 21, 492-504. [CrossRef]

14. Lo, A.Y.; Spash, C.L. Deliberative monetary valuation: In search of a democratic and value plural approach to environmental policy. J. Econ. Surv. 2013, 27, 768-789. [CrossRef]

15. Spash, C.L.; Aslaksen, J. Re-establishing an ecological discourse in the policy debate over how to value ecosystems and biodiversity. J. Environ. Manag. 2015, 159, 245-253. [CrossRef] [PubMed] 
16. LAWA-German Working Group on Water Issues of the Federal States and the Federal Government. Handlungsempfehlung für die Begründung von Fristverlängerungen mit Unverhältnismäßigem Aufwand Produktdatenblatt 2.4.3. 2013. Available online: http://www.wasserblick.net/servlet/is/ 142651/WRRL_2.4.3_Fristverlaengerung_final.pdf?command=downloadContent\&filename=WRRL_2.4.3_ Fristverlaengerung_final.pdf (accessed on 24 July 2017). (In German)

17. Ammermüller, B.; Klauer, B.; Bräuer, I.; Fälsch, M.; Kochmann, L.; Holländer, R.; Sigel, K.; Mewes, M.; Grünig, M. Cost-Benefit Assessment within the Context of the EC Water Framework Directive-Method for Justifying Exemptions Based on Disproportionate Costs; Logos-Verlag: Berlin, Germany, 2011.

18. Sigel, K.; Klauer, B.; Schiller, J. Begründung "weniger strenger Umweltziele” nach EG-Wasserrahmenrichtlinie mit Unverhältnismäßige Kosten—ein Verfahrens-vor-schlag. Korrespondenz Wasserwirtschaft 2015, 8, 768-774. (In German)

19. Martin-Ortega, J.; Skuras, D.; Perni, A.; Holen, S.; Psaltopoulos, D. The disproportionality principle in the WFD: How to actually apply it? In Economics of Water Management in Agriculture; Bournaris, T., Berbel, J., Manos, B., Viaggi, D., Eds.; SRC Press: Boca Raton, FL, USA; London, UK; New York, NY, USA, 2014.

20. Klauer, B.; Rode, M.; Petry, D. Flussgebietsmanagement Nach EG-Wasserrahmenrichtlinie; Metropolis-Verlag: Marburg, Germany, 2008.

21. Klauer, B.; Rode, M.; Franko, U.; Mewes, M.; Schiller, J. Decision support for the selection of measures according to the requirements of the EU Water Framework Directive. Water Resour. Manag. 2012, 26, 775-798. [CrossRef]

22. Klauer, B.; Schiller, J.; Bathe, F. Concept for cost-effective improvement of river morphology. J. Environ. Plan. Manag. 2014, 58, 1944-1960. [CrossRef]

23. Rode, M.; Klauer, B.; Petry, D.; Volk, M.; Wenk, G.; Wagenschein, D. Integrated nutrient transport modelling with respect to the implementation of the European WFD: The Weiße Elster Case Study, Germany. Water SA 2008, 34, 490-496.

24. Klauer, B.; Sigel, K.; Schiller, J.; Hagemann, N.; Kern, K. Unverhältnismäßige Kosten nach EG-Wasserrahmenrichtlinie: Ein Verfahren zur Begründung Weniger Strenger Umweltziele; UFZ-Bericht 01/2015; Helmholtz Centre for Environmental Research (UFZ): Leipzig, Germany, 2015.

25. Brack, W.; Dulio, V.; Agerstrand, M.; Allan, I.; Altenburger, R.; Brinkmann, M.; Bunke, D.; Escher, B.I.; Hollert, H.; Kase, R.; et al. Towards the review of the Water Framework Directive: Recommendations for more efficient assessment and management of chemical contamination in European water resources. Sci. Total Environ. 2017, 576, 720-737. [CrossRef] [PubMed]

26. Klauer, B.; Manstetten, R.; Petersen, T.; Schiller, J. The Art of Long-Term Thinking: A bridge between sustainability science and politics. Ecol. Econ. 2013, 93, 79-841. [CrossRef]

27. Klauer, B.; Manstetten, R.; Petersen, T.; Schiller, J. Sustainability and the Art of Long-Term Thinking; Routledge: London, UK, 2016.

(C) 2017 by the authors. Licensee MDPI, Basel, Switzerland. This article is an open access article distributed under the terms and conditions of the Creative Commons Attribution (CC BY) license (http://creativecommons.org/licenses/by/4.0/). 